\title{
Small-Group Presentation as Medium for Students to Practise Analyzing Literary Works
}

\author{
Rima Devi ${ }^{1, *}$ Rachmidian Rahayu ${ }^{1}$ Aulia Rahman ${ }^{1}$
}

\author{
${ }^{1}$ Japanese Department Universitas Andalas \\ ${ }^{*}$ Corresponding author. Email:rimadevi@hum.unand.ac.id
}

\begin{abstract}
Analyzing literature work using literary theory for students in the Undergraduate Program of Japanese Studies, Universitas Andalas has not become prevalent. Students still focus on the subject related to Japanese language skills, which is an absolute requirement to graduate and hold a bachelor's degree. However, for students who are interested in literature and writing a thesis on literature, in addition to the ability to read Japanese literary works, they are also required to be able to analyze these works. Most of the students majoring in literature have difficulty in writing ideas. Thus, the sociology of literature subject that examines social issues contained in literary works carried out a group presentation method. Lectures divide students into small groups of 3 to 4 students. Then, each group made a brief paper with three parts: the intrinsic elements, social issues in work, and analysis of the work related to the data with the sociology theory. Each group had the opportunity to present three times with the three parts described above. Students and their groups of peers discuss a literary work, analyze it together, and then present the analysis results to the class. The implementation of this group presentation teaching method has known that students have an easier time understanding how to analyze literary works. Students have trained themselves to convey their ideas and thoughts after analyzing literary works through oral and written.
\end{abstract}

\section{Keywords: Group Presentations, analyzing literary works, Japanese literature, literature lecture}

\section{INTRODUCTION}

Literary work is a medium to express the author's feelings, ideas, and thoughts to the reader. The author does not just release his heart and mind to the reader but also conveys a hidden message. There are many reasons why the author does not directly convey his thoughts in the work he writes. Sometimes the author also does not realize that he has conveyed the various things that happen around him in his work so that literary works can be used as a medium for reading or knowing how the author's image at the time the author lived. Researching or studying the things depicted in literary works is a particular pleasure, especially when it is possible to connect to form one thought. We can apply this methodology in the sociology literature approach.

The Sociology Literature is a compulsory elective subject offered in the fifth semester, with two credits. Students of the Japanese Studies Program in Universitas Andalas must take this Subject with a literary interest, namely those who will write a final project or thesis on
Japanese literature. This Subject discusses the relationship between literary works and authors, readers, and society. This Subject's focus is on literary works, which are considered socio-cultural documents, sociocultural influences on the creation of literary works, and society's acceptance of literary creation. The purpose of giving this Subject is to understand the sociology of literature approach to analyzes literary works. As a result, students can apply sociological theories to study Japanese literary works.

This Subject is held based on the Graduate Learning Outcomes set by the Japanese Study Program Universitas Andalas. These achievements include knowledge, general and specific skills, attitudes, and values. The Japanese Studies Program has written in subjects' learning outcomes, such as showing a religious attitude, upholding moral values, ethics, norms, respecting diversity, and showing a responsible attitude. For the knowledge section, the subject result expects the student to master fundamental theories and concepts regarding Japanese literature, culture, and society, master knowledge, 
cultural insights, and think scientifically in an Indonesian and global context to support their professional activities.

Meanwhile, the general abilities that the subject result expect students to gain through this Subject are being able to apply logical, critical, systematic, and innovative thinking in the context of developing or implementing science and technology that pays attention to and applies humanities values according to their field of expertise; able to demonstrate independent, quality, and measurable performance; able to study the implications of the development or implementation of technological science that pays attention to and applies humanities values according to their expertise based on scientific principles, procedures and ethics in order to produce solutions, ideas, designs or art criticism, compile scientific descriptions of the results of their studies in the form of a thesis or assignment report end, and upload it on the college page; able to make decisions appropriately in the context of problem solving in their area of expertise, based on results of information and data analysis. For special abilities, subject results expect the student to have the ability to write scientific works based on theories, concepts of literature, linguistics, and culture related to the fields of literature, linguistics, and Japanese culture.

Regarding the teaching materials used in this lecture, none has developed yet. The Literature Sociology subject team determines the themes or topics to be discussed and provides references for students to read, then each meeting in the class discusses predetermined topics. The lecturer has not carried out the development of teaching materials yet because this Subject's focus is not on providing material to students. This Subject emphasizes gradually to train students to understand Japanese literature, Japanese socio-culture, and applying sociological theories in analyzing literary works in general and Japanese literature in particular.

Regarding teaching methods, generally, lectures that explain theory are carried out by the lecture method. However, this method is not adequate, especially in terms of students' understanding of the material. The SCL (Student Center Learning) method has begun to be applied by providing specific topics and related references in recent years. Students in groups present and discuss them. The lecturer assesses students from the presentation and group discussion, class activity, and mid and final semester exams. The distribution of student grades generally ranges from $\mathrm{A}, \mathrm{A}-\mathrm{B}, \mathrm{B}+, \mathrm{B}, \mathrm{B}-$, and $\mathrm{C}$.

Some students' grades are less than $\mathrm{C}$. The students who get $\mathrm{C}$ are usually because they often do not attend lectures; they are not actively involved in group discussions, and cannot answer exam questions.

Overall, there are no apparent problems with the teaching methods applied so far. However, in terms of students' ability to digest and analyzes literary works, there is no significant progress. Students understanding the material are still at the level of understanding on its surface and have not touched the core. The problem appears when students start writing their thesis; many do not understand how to analyzes literary works. Furthermore, what is more, surprising is that there are students who have not been able to put their ideas and thoughts into writing correctly. The teaching team's observation and discussion concluded that the students' weak ability to write and analyzes resulted from the lack of an opportunity for them to practice for that. The problems faced after the lecture are completed and continued to the stage of writing research proposals and theses. Based on this problem, this research aims to train students to present and write their analysis results.

\section{METHODS}

SCL (Student Centre Learning) is a method used in sociology literature lectures. Moreover, small-group presentations are applied as a medium for student presentations. The presentation process is the students present in small groups and a theme each presentation that has been determined by the lecturer. The general theme is to discuss social institutions contained in literary works. In order to have similarities with each group at lecture result, lectures choose literary works of the same author, the same genre, the same theme, or other things that characterize each other's similarities.

First, the lecturer divided the student into several small groups consisting of 3-4 people to carry out the activities. Each group made three presentations. In the first presentation, each group received one literary work and presented the intrinsic elements in the literary work. The purpose of presenting these intrinsic elements is to understand the content of literary works that can be discussed more comprehensively. Students can also discuss with each other so that it triggers them to find interesting ideas at work. The lecturer only acts as a facilitator. The lecturer also directs students at the end of the discussion about social institutions in literary work.

The second round of presentations is that each group presented the social institutions in literary works and linked them to sociological theories. In this case, the lecturer expected the student to understand the social context contained in literary works. In the third-round presentation is each group analyzed the work using the social context discussed in the previous presentation using sociological theory. In this third-round presentation, the lecturer played a more role in directing students to provide strong arguments in their analysis. After each group has completed three presentations, students in groups are guided by a lecturer to write articles based on their presented material. However, when students do the three stages of presentation, their brief papers that will be distributed to the audience are done together in groups without the lecturer's guidance.

The standard grade distribution is that students get maximum scores, namely $\mathrm{A}, \mathrm{A}-$, and $\mathrm{B}+$ only. This grade gap is carried out based on student performance 
during the lecture process, and the lecturer expects that no one will get a score less than grade standard. The assessment is not taken based on middle test assessment or final assessment. The assessment is taken from student's activeness during the lecture process, including preparing and conducting presentations, understanding the material, and writing articles.

Student response in this lecture is a measure of the success of the established lecture method. The response is filling out a questionnaire containing student responses regarding the Subject of the ongoing Subject of revision and their input and suggestions for future lecture improvements.

Several lecturers have carried out similar research in various fields of science, social sciences, and humanities. These lecturers develop presentation methods in small or large groups. This method can train students' communication skills and make them able to understand the content and context at once [1]. The lecturer finds a satisfactory result from implementing presentation methods in learning foreign languages such as English. Students can learn new vocabularies through their presentations. The presentation's topic was replaced with exciting things in the world, such as the problem of global warming, to build a dynamic atmosphere in the class. Students who take this course feel that the lecture is useful, and the methods applied help understand the course material [2]. Furthermore, the presentation group method, besides being able to help students understand lecture material, students can also assess their abilities so that they can improve competence [3].

\section{RESULTS AND DISCUSSION}

This research focuses on media and learning technology in the Sociology of Literature Subject designed by the Japanese Studies Program, Faculty Humanities, Universitas Andalas. The media chosen are small group presentations and articles produced by students during the lecture. This lecture's theme is social institutions depicted in the novel by the Japanese novelist, Ogawa Yoko. The selection of novels by Ogawa Yoko is based on the research of one of the lecturers. It hopes that the harmony between the selected novelists will form a mutually sustainable narrative.

Twenty students are taking the Sociology of Literature Subject on the even semester of the 2019/2020 academic year. The lecturer divides the student into six groups. One group consists of 3 to 4 people. Each group obtains a Japanese novel with the tanpen genre written by Ogawa Yoko. Tanpen is a Japanese novel that is not very long, ranging in content from 10 - 30 pages.

The lecturer divided the lectures into four stages; namely, three lecture stages carried out by three lecturers, and one final stage is guidance on writing papers. Each stage consists of 4 meetings, bringing the total to 16 meetings. This number of meetings has met the requirements set by Universitas Andalas. In this lecture, the lecturers carried out neither the middle test assignment nor the final assignment. The lecturer takes middle and final assessments from paper writing assignments and student presentations.

Lectures in the first stage and the first meetings are the explanation and material delivery by the lecturer. In addition to providing material at the first meeting, the lecturer divided the group based on tanpen written by Ogawa Yoko. The material introduces the sociology of literature and an explanation of the lecture contract and assignments. At the second to the fourth meeting are presentations by students. One meeting held presentations by two groups up to the fourth meeting. Students' presentations in the first stage of the lecture explored the novel's intrinsic elements and discussed social institutions studying from the tanpen. The presenting groups share a brief paper on the intrinsic elements they have written in a group with the audience.

The second stage of the lecture is the fifth meeting, an explanation by the lecturer about social institutions in society in general and Japanese society. Students also explained the material at the fifth meeting, namely the social institutions in their respective tanpen. The next three meetings were student presentations about this social institution.

The lecture in the third stage is the ninth meeting. The lecturer explained how to analyze literary works using the sociology of literature approach. Students were assigned to analyze their respective tanpen to present at the next three meetings with understanding the novel's intrinsic elements, the social institutions in the tanpen, and sociological theory. The lecture in the second and threestage, students distribute a brief paper to discuss to the audience.

The lecture in the fourth stage is paper writing guidance. Students' material in the third stage lecture is to write in an article by each group based on the lecturer's guidance. Each lecturer gets two groups of guidance. This mentoring period runs for four meetings.

The final stage of the lecture was not carried out as planned. It happened because lectures were converted into online lectures in connection with the outbreak of the Covid-19. The lecturer has not yet gotten the right method for implementing the remaining lectures, namely in article writing guidance. The articles that initially had to be completed were still not finished. Students also constrain from discussing with a group of peers because they only meet online and have not been effective. However, lectures and article writing guidance can carry out with all limitations.

The successful application of this presentation method is to know from the papers written by students. So far, it seems that students have begun to understand how to analyze literary works using the sociology of literature approach. Students also begin to practice writing their ideas in an article. The student improvement is to know 
from the three brief papers presented in the previous three lecture stages.

Apart from students' brief papers, the application of this method is to know from student responses. Twenty students were attending the lectures, and 19 people are filling out the questionnaire. Students stated that they could understand the teaching material through the group presentation method as $63.2 \%$. Simultaneously, the rest stated that they still need an additional explanation from the lecturer to understand the material. It happened because students who present the material are still learning how to explain the material thoroughly. The student has spoken to the lecturer that they did not understand a material trough the peer's presentation only. Moreover, for the solution at the end of each lecture, the lecturer provides feedback on each presentation.

Regarding writing the final article, which summarizes all the material, $52.6 \%$ of students are more likely to choose to write articles individually and the rest in groups. It happened because each student has their style of writing. Nevertheless, to write a brief paper for each presentation, it does not matter if it is done in groups because they can discuss its material.

\section{CONCLUSION}

The presentation method in small groups can be used to train students to be able to convey ideas orally. Preparation of students before the presentation, namely understanding the material, then writing in the brief papers in groups can help students to train themselves to write their ideas and thoughts in writing. The presentation method is an effective method to help students to understand teaching material and to practice conveying their ideas, either orally or in writing. Regarding writing the whole idea in articles, students prefer to work by themselves rather than in groups.

\section{ACKNOWLEDGMENTS}

This work was supported by LP3M Universitas Andalas, Kampus Limau Manis, Padang, 25163, Indonesia.

\section{REFERENCES}

[1] Haber,R.J.,Lingard,L.A.Learningoralpresentation skills. J GEN INTERN MED 16, 308-314 (2001). DOI:https://doi.org/10.1046/j.15251497.2001.00233. $\mathrm{X}$

[2] Lee, E. \& Park, M. Student presentation as a means of learning English for upper intermediate to advanced level students. Journal of Pan Pacific Association of Applied Linguistics, 12(1), 47-60, 2008
[3] Smith, Charlene M. \& Sodano, Todd M. Integrating lecture capture as a teaching strategy to improve student presentation skills through self-assessment. Sage Journals. $2011 . \quad$ DOI: https://doi.org/10.1177/1469787411415082 